\title{
ANALISYS OF DIRECT PAYMENTS DISTRIBUTION IN BULGARIAN AGRICULTURE
}

\author{
R. Beluhova-Uzunova*, D. Atanasov, K. Hristov \\ Department of Economics, Agricultural University - Plovdiv, Plovdiv, Bulgaria
}

\begin{abstract}
Direct payments are the main component of the Common Agricultural Policy (CAP). They form approximately $76 \%$ of CAP budget in the programming period 2014-2020. The main purpose of the study is to outline the opportunities and challenges for Bulgarian agriculture, based on the analysis of direct payments distribution. The Lorenz curve, as the most widely used measure of inequality, is applied in the paper to surveying the disparities in the direct payments distribution. The results of the analysis show highly uneven distribution of the direct support across Bulgarian farms. The Lorenz curve indicates that payments are accumulated mainly in the larger-scale farms, thereby generating problems for small holdings and structural imbalances. The allocation of EU funds has impacted on the level of investments, productivity and economic efficiency of Bulgarian agriculture.
\end{abstract}

Key words: EU, CAP, agricultural holdings, support, inequality, Lorenz Curve

\section{INTRODUCTION}

Main objectives and instruments of the Common Agricultural Policy changed progressively in its 50 years history. One of the most important results of the transformation is the evolvement from a product-specific policy to a producer-specific policy. In 1992, the MacSharry reform introduced the direct payment. Agenda 2000 continued further with the changes. Fischler reform in 2003 finally presented "first pillar" of the CAP with The Single Payment Scheme (SPS) and the Single Area Payment Scheme (SAPS) in the new Member States.

The information presented by annual publications of European Commission shows the importance of direct payments as a main instrument of CAP for all Member states, including Bulgaria. According to the European Commission in financial year 2006 (the first year of implementation of the 2003 reform), direct payments reached $€ 33.7$ billion (65\% of the total CAP budget), and only $4 \%$ of them were decoupled. In financial year 2015 (calendar year 2014), direct payments reached $€ 42.2$ billion and represented $74 \%$ of the whole CAP budget and $93 \%$ of them were decoupled. (1)

\footnotetext{
*Correspondence to: Rositsa Beluhova-Uzunova, Department of Economics, Agricultural University - Plovdiv, 12 Medeleev Bld., 4000 Plovdiv,

Bulgaria, e-mail: rosicab_uzunova@abv.bg, Mobile phone: +359883326543
}

Direct payments support in Bulgaria for the financial year 2015 was $€ 643$ Million, 91\% of which was decoupled. (2). Bulgarian agricultural structure changed significantly after the accession to the European Union. This transition included transformations in the specialization as well as in the concentration of agricultural production. The CAP support is very important in Bulgaria and leads to various positive changes as an increase of the utilized agricultural area and growth in the investments in the sector. However, the CAP implementation caused severe imbalances and polarization of agricultural structure. The beginning of the programing period 2014-2020 gives good opportunity to analyze and highlight the role of direct payments distribution in these processes. This topic is widely discussed and extends to debate about distribution of the direct support among the farmers.

The main purpose of the study is to outline the opportunities and challenges for Bulgarian agriculture based on the analysis of direct payments distribution.

The paper is structured as follows. First, the study presents a brief preview on literature of distributive aspects of direct support and the methodology of the paper. Second, the survey shows comparison of direct payments distribution between Bulgaria, EU - 12 and EU- 28. In the third part are highlighted 
alternatives and challenges in the programing period 2014-2020.

\section{MATERIALS AND METHODS}

Many authors analyzed different aspects and prospective of direct payments. OECD looked at the consequences of agricultural policies on the distribution of farm income $(3,4)$. After Agenda 2000 the topic of direct payments distribution is discussed by various studies in Europe (5-10).

Other authors pointed that in general big holdings have received financial support disproportionately compared to small farms, generating situations of disequilibrium that have impacted on levels of investment, productivity and economic efficiency of farms (11-13). Several reports published by EU institutions (14-16) presented analyses of economic and distributional consequences of direct payments for the agricultural sectors in the EU after the CAP reform of 2003.

Sinabell et al. (10) observed distribution of direct support among farms in all Member states in $2000-2010$. Comparison between countries is provided in the paper by using Gini Coefficient and Lorenz Curve. This is the first survey after 2003 reform that analyzed not only the distribution of direct payments, but also the evolution of the direct support over the years.

Although there are many studies that present the effects of policy intervention, the aim of this survey is to analyze only one type of instrument - the direct payments of the CAP and their distribution in Bulgaria. For that purpose Lorenz curve is applied as a one of the most accurate methods.Lorenz curve and Gini coefficient are the most widely used measures of inequality. The Lorenz curve presents income distributions as proposed by Lorenz (17). This approach is conceptually very similar to the method by quantiles. Functional relation proposed by Rasche et al.(18) is used in the survey to estimate Lorenz curves. In the equation 1 is shown the explicit functional form.

$$
\begin{aligned}
& y=\left[1-(1-x)^{\alpha}\right]^{1 / \beta} \\
& \text { where } 0<\alpha \leq 1,0<\beta \leq 1
\end{aligned}
$$

The function possesses the proper convexity and slope constraints to assure that it always lies in the lower triangle of the unit square (18).

The Lorenz curve compares the cumulative proportion of direct payment units (holdings), $x$, to the cumulative proportion of direct payment received, y, when units are arranged in ascending order of their direct payments. Eurostat provides data for twelve classes of farms $(x)$ and direct payments received $(y)$, of which cumulative proportions are calculated.

\section{DISTRIBUTION OF DIRECT PAYMENTS IN BULGARIA}

Lorenz curves are a graphical presentation of inequality (17). This allows visual impression of direct payments distribution. Three important comparisons between Bulgaria and other Member states are observed in the study.

After the accession to EU, the structural changes caused more unequal distribution of the direct support in Bulgaria (Figure 1). Financial years 2008 and 2015 are calendar years 2007 and 2014. This analysis shows the evolution and transformation of the financial support in Bulgaria. Lorenz curve shows that the inequality of direct payments distribution in the country increased significant between 2008 and 2015. In $201586 \%$ of the holdings received only $15 \%$ of direct support. On the other hand more than $67 \%$ of the DP support goes to less than $3 \%$ of the farms. The biggest $1,4 \%$ of the farms receive more than $42 \%$ of the support.

In $200893 \%$ of the beneficiaries received $22 \%$ of the direct payments and $0,2 \%$ of the holdings concentrated around $20 \%$ of the support. Almost $50 \%$ of the support is concentrated in less than $1 \%$ of the farms. The census conducted in 2013 shows that there is downward trend in the number of farms. For the period 2003-2013 the reduction of the holdings is nearly $62 \%$. The level of concentration increased noticeably and there is major growth in size of the total UAA. Wider study of the data, however, reveals structural imbalance. Irrational structure of farms is established in the country and there are major disparities in the level of concentration (Census 2010 and FSS 2013). The study indicates that the concentration increased due to the disappearance of small farms. The significant share of UAA (more than $75 \%$ ) is concentrated in less than $3 \%$ of the total number of the farms (large structures over 100 hectares). The average for EU-28 is approximately 50\%. Smaller farms are disappearing and medium-sized holdings remain with a negligible share in the country's total. These are the main problems in the agricultural structure in Bulgaria and the major reasons for the inequality and imbalance in financial distribution among the beneficiaries. 


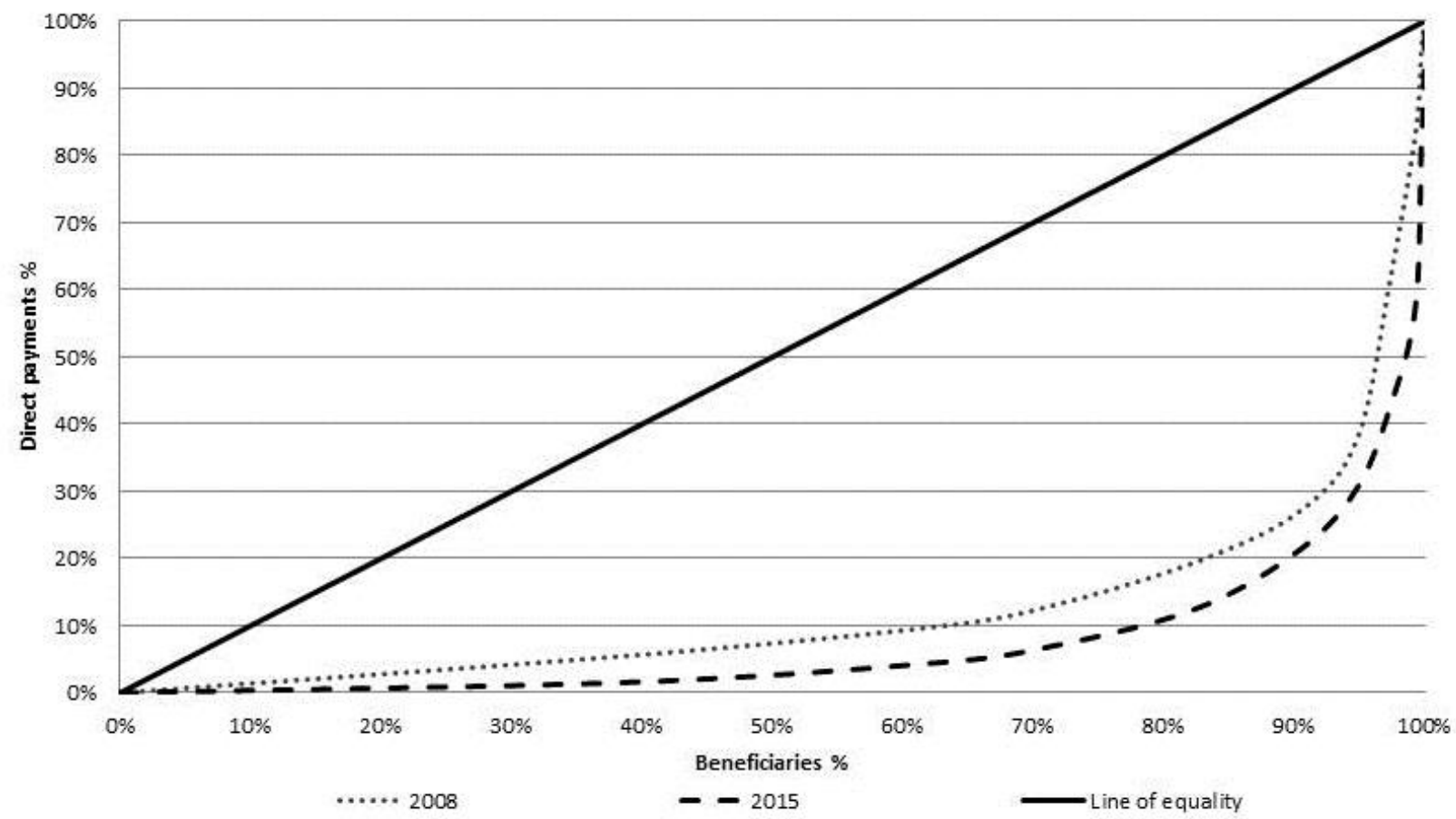

Figure 1. Comparison of direct payments distribution in Bulgaria (2008-2015)

Figure 2 shows comparison of the direct payments distribution between Bulgaria and EU-28 in 2015. The curve of Bulgaria moves progressively closer to the curve of the EU-28, which indicates that the country has similar structure of direct payments distribution. However, the distribution of financial support is unequal in EU-28 and leads to serious debates among the member-states. On average, $80 \%$ of the beneficiaries receive less than $20 \%$ of the payments in EU-28. The main differences between Bulgaria and EU-28 could be observed in the group of medium sized farms. In EU-28 this group receives around $50 \%$ of all support, and represents $19 \%$ of the farmers. In Bulgaria the number of medium sized farms is five times smaller $(10 \%$ of all beneficiaries), and the total support received $30 \%$ of the payments.

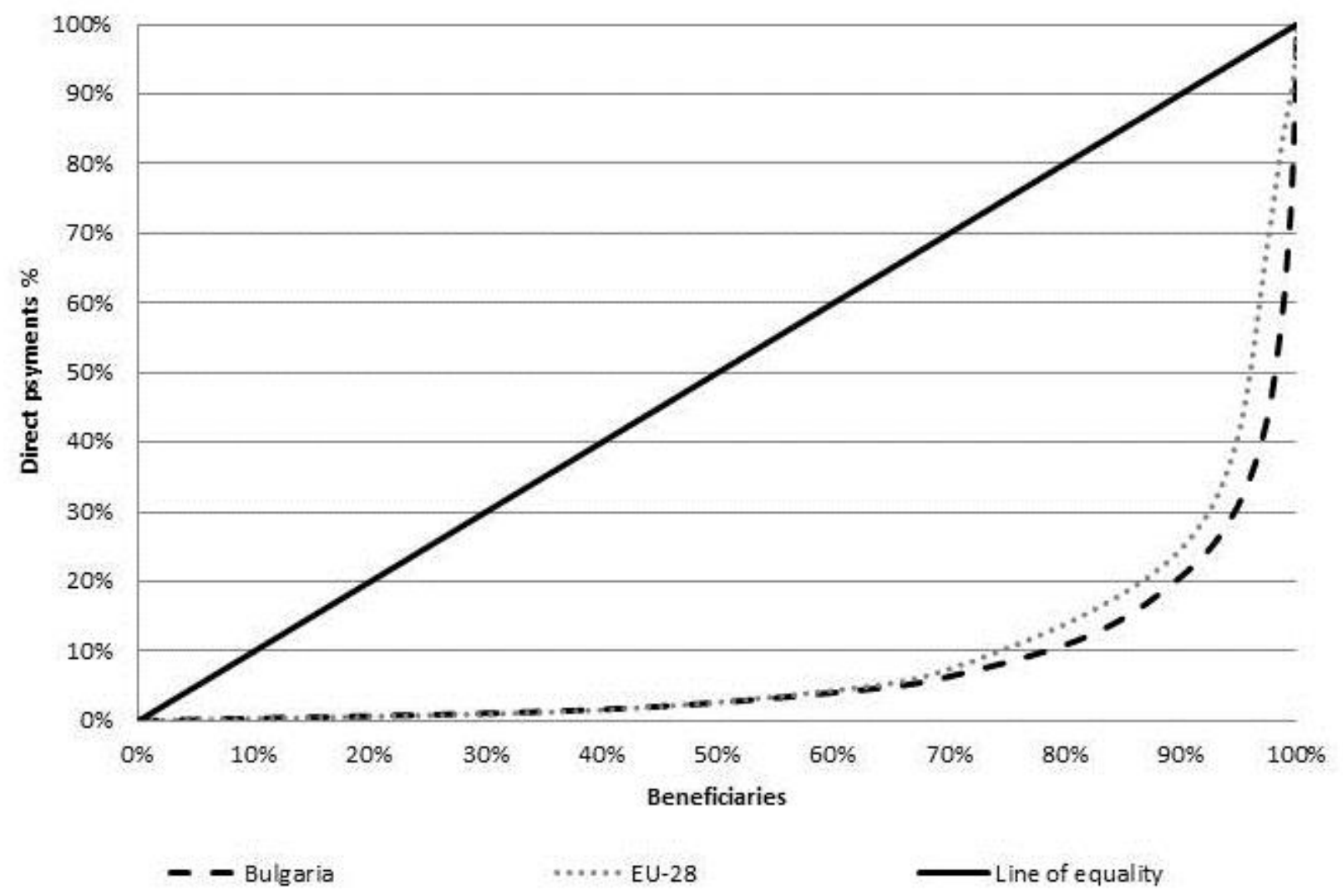

Figure 2. Direct payments distribution in Bulgaria and EU-28 
The other important distinction could be associated with the overconcentration of financial support in large farms in Bulgaria. Big farms accumulate major financial aid but are only around 1,4\% of all holding making polarization of farm structures one of the major problems in Bulgaria. The distribution of direct payments between small and large farms is regularly discussed in EU from the point of view of social cohesion. Commission has proposed various mechanisms to limit the amount of direct payments that could be received by single farmer in order to make the distribution of direct support fairer.
EU averages do not reflect the changes that occur in the individual Member States. The EU-28 data is seriously influenced by the effect of the 2004 and 2007 enlargement, which brought a number of small farms into the EU. Therefore, a survey on groups of countries could be more accurate.

The comparison between Bulgaria and EU-15 (Belgium, Denmark, Germany, Ireland, Greece, Spain, France, Italy, Luxembourg, the Netherlands, Austria, Portugal, Finland, Sweden and the United Kingdom) shows significant differences, illustrated in Figure 3.

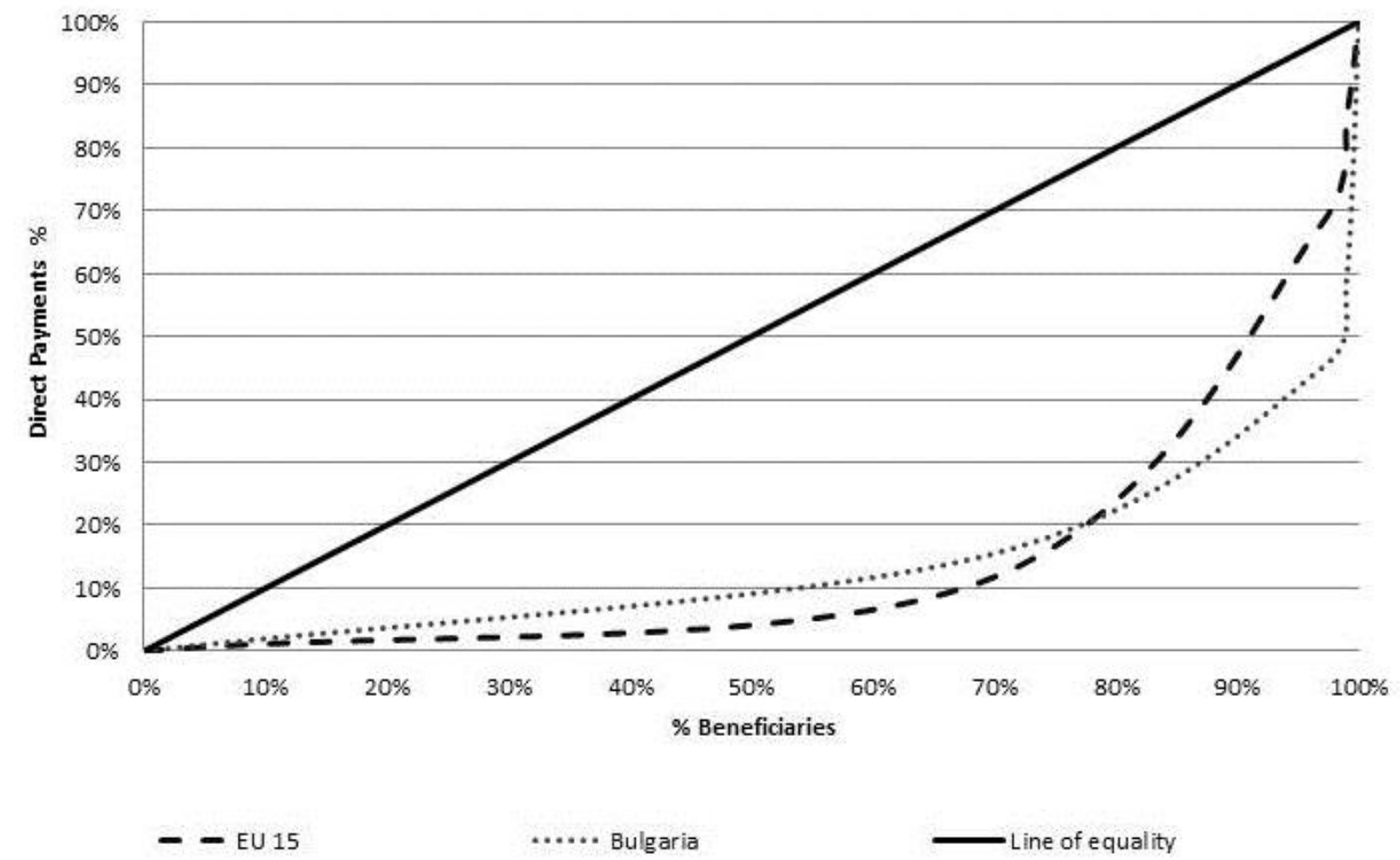

Figure 3. Direct payments distribution in Bulgaria and EU-15

The distribution in EU-15 countries is more equal compere to the Bulgarian perspective. Lorenz curve indicates severe differences between Bulgaria and Member states in 2003. There are three substantial distinctions. First, in EU-15 69\% of beneficiaries receive less than $€ 5000$ while in Bulgaria there are $86 \%$ in this group. The second and more important difference is the share of farms receiving $€ 5000$ to $€ 50000$ (medium sized farms). These holdings are $28 \%$ of all beneficiaries and receive $57 \%$ of the financial support in EU-15. In Bulgaria the share of these farms is three times smaller, and they accumulate only $30 \%$ of financial support. The third difference is related to the concentration of direct payments in large structures. In EU-15 and Bulgaria the share of these beneficiaries is similar, but in EU-15 they receive $17 \%$ of all payments which is significantly lower compere to Bulgaria where they accumulate more than $40 \%$ of the support.

The structure of agricultural holdings in Bulgaria is characterized by overconcentration of support in large farms and insignificant share in small holdings. After the accession to the EU the share of Small producers in the total number of farms noticeably reduces. The decrease of small farms is caused by the suspension of their activity, rather than increasing in their size. On the other hand large structures are growing and their increase does not correspond to the changes in small and medium sized farms. After CAP implementation in Bulgaria, despite there is some positive changes, the structure of holdings is characterized with unbalanced distribution, dominance of large producers and the insignificant role of medium-sized farms. 
The positive changes have to be considered, but unfortunately too many challenges remain and too many improvements have to be made for better and more rational agricultural development. Along with the advantages of the implementation of CAP, many problems occurred. Irrational dualistic structure of agriculture is established. The direct payment support in the period 2007-2013 is highly uneven. The funds are turned to large holdings. Small farms, unable to reach this support are disappearing. These farms are essential for the sustainable development of rural areas and struggling against poverty. Without supporting small farms we could not expect any positive changes in the rural areas.

\section{THE NEW CAP - NEW CHALLENGES AND OPPORTUNITIES}

The new reform in CAP and the new parameters influence national agricultural policies and are changing public support in agriculture. Higher flexibility is provided to Member States in applying direct payment support measures with the concern of more fairly distribution among the farms.

CAP reform 2014-2020 introduces some important changes (new architecture of direct payments, green direct payment etc.). The new system ensures that $30 \%$ of direct payments will be conditional upon respect of agricultural practices beneficial for the climate and the environment. This green payment can be provided as a flat rate or in proportion of the basic payment to farmers. According to Eurostat only $14 \%$ of EU farmers are under 40 years of age and therefore, from 2015, all young farmers entering the sector could get an additional payment.

Member States also have the opportunity to give direct payments through other schemes. A redistributive payment can be attributed to the first hectares of the farms. This scheme aims at providing more funds to small and mediumsized farms. A specific and simplified support scheme for small farmers was introduced in order to facilitate their access to direct payments and reduce the administrative burden. Member States have the opportunity to grant limited coupled support to secure potentially vulnerable sectors in the countries. Therefore the CAP in different countries could potentially vary significantly.

Direct payments are about $70 \%$ of CAP budget and therefor are very important topic of discussions across the Community. Differences in the support, noticeable after the enlargements in 2004 and 2007 are a big issue for the new Member States, especially the three Baltic States, Romania and Bulgaria. The reform from 2013 is not only cutting the direct payments, but also allocating relatively more support for those member states where payments are below 90 percent of the EU average. These changes are supposed to be financed by members with above EU average payments.

The other important feature of CAP is the possibility for transferring of funds between the two pillars of the CAP.

In the programming period 2014-2020 the EU has an effort to reduce disparities through a mixed system of financial supports and aids. The 2013 CAP aims at decreasing the degree of inequality in the distribution of payments through two mechanisms degressivity/capping and the redistributive payments. The impact of these instruments will not be visible until the Commission publishes its next report which will give information on the distribution of payments made to farmers in 2015, the first year of implementation of these reforms. Theoretically, Bulgaria could benefit from the new regulations in terms of overcoming structural imbalances. The concentration of direct payments in the period 2007-2013 caused significant polarization in Bulgarian agriculture. In the new period CAP is more flexible and allows Member States to use different measures regarding the specifics of the countries. Strong political will is needed in order to direct the financial support to priority sector with high value added in order to reduce regional and structural differences.

\section{REFERENCES}

1. European Commission, Indicative figures on the distribution of direct aid to farmers, financial year 2015, 2016

2. European Commission, Report on the distribution of direct aid to farmers, financial year 2015, 2016

3. Moreddu, C., Distribution of support and income in agriculture. OECD food, agriculture and fisheries working papers, no. 46. OECD, Paris, 2011

4. OECD, Evaluation of agricultural policy reforms in the European Union. OECD, Paris, 2011

5. El Benni N. and Finger, R., The effect of agricultural policy reforms on income inequality in Swiss agriculture - an analysis for valley, hill and mountain regions. J Policy Model 35(4):638-651, 2013,

6. Schmid, E., Hofreither, M., Sinabell, F., Impacts of CAP instruments on the distribution of farm incomes-results for 
Austria. Discussion paper DP-13-2006, Universität für Bodenkultur Wien, 2006

7. Severini, S., Tantari, A.,The impact of agricultural policy on farm income concentration: the case of regional implementation of the CAP direct payments in Italy. Agric Econ 44(3):275-286,2013

8. Severini,S., Tantari,A.,The effect of the EU farm payments policy and its recent reform on farm income inequality. J Policy Model 35(2):212-227, 2013

9. Keeney,M.,The distributional impact of direct payments on Irish farm incomes. J Agric Econ 51(2):252-265, 2000

10. Sinabell F. et al., Exploring the distribution of direct payments of the common agricultural policy. Empirica 40(2):325341, 2013

11.Mishra, A, et. al., Effect on agricultural policy on regional income inequality among farm households. J Policy Model 31(2009):325-340,2009

12.Galluzzo, N., Farm dimension and efficiency in Italian agriculture: a quantitative approach, American Journal of Rural Development, 1 (2), 26-32.,2013

13. Galluzzo, N. , Role and effect of agroforestry subsides allocated by the Common Agricultural Policy in Italian farms, International Journal of Food and Agricultural Economics, 3(1), 19-31, 2015

14.European Commission, CAP Health check-impact assessment note no. 1. Directorate-General for Agriculture and
Rural Development, Directorate G. Economic analysis, perspectives and evaluations, Brussels, 2008

15.European Commission, Developments in the income situation of the EU agricultural sector. Directorate-General for Agriculture and Rural Development, Directorate L. Economic analysis, perspectives and evaluations, Brussels, 2010

16.European Commission, Proposal for a Regulation of the European Parliament and of the Council establishing rules for direct payments to farmers under support schemes within the framework of the common agricultural policy. COM (2011) 625 final/2, Brussels, 19 Oct 2011

17.European Court of Auditors, Single payment scheme (SPS): Issues to be addressed to improve its sound financial management. Special report no 5, Luxembourg, 2011

18. Agrosynergie, Evaluation of income effects of direct support. Final Report of Framework contract no. 30-CE0223110/00-78. EEIG AGROSYNERGIE, Brussels, 2011

19.Lorenz, MO, Methods of measuring the concentration of wealth. Quarterly Publications of the American Statistical Association, 9 (new series, no. 70): 209219,1905

20.Rasche, RH, et. al., Functional forms for estimating the Lorenz curve. Econometrica 48(4):1061-1062, 1980 